\title{
Ectopic gestation in a tubal stump
}

\author{
S. KRZANIAK \\ M.B., B.Chir., B.A.O., M.R.C.O.G. \\ Former Registrar in Obstetrics and Gynaecology, \\ Central Middlesex Hospital, Park Royal, London, N.W.10
}

Pregnancy in a remnant of a Fallopian tube is very rare and although a case of a primary abdominal pregnancy attached to a tubal stump was reported by Corti \& Ronaldi (1964) the author is not aware of any case reports of a pregnancy occurring in a tubal stump. We wish to report a case of an extrauterine gestation in the proximal end of a Fallopian tube following ipsilateral salpingo-oophorectomy.

\section{Case report}

The patient was a 30-year-old single negress who had had two previous normal confinements in 1952 and 1953. She was admitted to the Central Middlesex Hospital on 4 January 1966 complaining of an increasing generalized lower abdominal pain of $12 \mathrm{hr}$ duration, nausea and shoulder pain. An episode of similar abdominal pain lasting 1 day occurred 8 days prior to her admission. Vaginal bleeding interpreted as a period occured on 24 December 1965 and lasted 7 days. There was no vaginal bleeding on admission.

Menstruation had started at the age of 11 and the periods were regular, occurring every 28 days and lasting 7 days. Her last normal menstrual period was on 2 November 1965.

Inquiry into the past medical history revealed that an appendicectomy was performed in 1958. A second abdominal operation, during which a cyst was removed, was done in 1959 in Dominica.

On examination the patient looked ill. The mucous membranes were pale. Her pulse was weak, $104 / \mathrm{min}$., temperature $98^{\circ} \mathrm{F}$, BP $110 / 80$ $\mathrm{mmHg}$.

Cardiovascular and respiratory systems were normal. The abdomen was distended in the suprapubic area and acutely tender, particularly in both iliac fossae. There was also a marked rebound tenderness. The bladder was distended and contained $500 \mathrm{ml}$ of clear urine.

There was no vaginal bleeding. The cervix was firmly closed but very tender to touch. The uterus could not be outlined because of marked pelvic tenderness. Both adnexae were very tender and there was fullness in the pouch of Douglas.

Hb $53 \%(7.7 \mathrm{~g} / 100 \mathrm{ml})$. WBC $6300 / \mathrm{mm}^{3}$. ESR $11 \mathrm{~mm} / \mathrm{hr}$, blood group $\mathrm{O}$, rhesus-positive. A catheter specimen of urine showed no sugar or albumen and there were no pathogens.

A diagnosis of intraperitoneal bleeding due to a ruptured ectopic gestation was made, and laparotomy was performed.

Operation. The peritoneal cavity contained $1100 \mathrm{ml}$ of blood and blood clot. The right Fallopian tube and ovary were normal. The left Fallopian tube and ovary were absent. The uterus was slightly enlarged and contained a pedunculated fibroid, $2.0 \mathrm{~cm}$ in diameter, on its right anterior wall. There was active bleeding from the left uterine cornu. Closer examination showed that there was a $2.5 \mathrm{~cm}$ long tubal stump, a remnant of a previously performed salpingectomy, containing an ectopic pregnancy. The gravid stump was fibrosed at its distal end and was separated from the uterus by a definite narrowing, as illustrated in Fig. 1. The round ligament was on the medical aspect of the gravid swelling. The rupture occurred near the uterine wall.

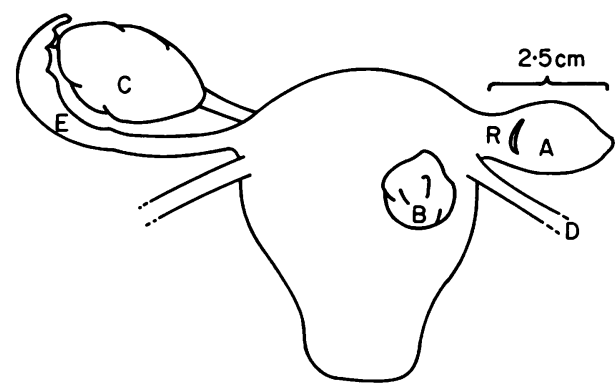

Fig. 1. Diagrammatic representation of uterus and tubal stump as found at laparotomy. A, tubal stump; B, fibroid; C, right ovary; $D$, left round ligament; $E$, right Fallopian tube; $R$, point of rupture. 
The stump containing the pregnancy was clamped off and excised. Haemostasis was secured and the blood was replaced by 4 pints of blood transfusion. The pedunculated fibroid was also removed.

Histological examination of the excised tubal stump confirmed ectopic tubal gestation by showing haemorrhagic trophoblastic perforation of a Fallopian tube containing normal immature chorionic villi, as shown on the accompanying photograph of a section of the excised tubal stump (Fig. 2).

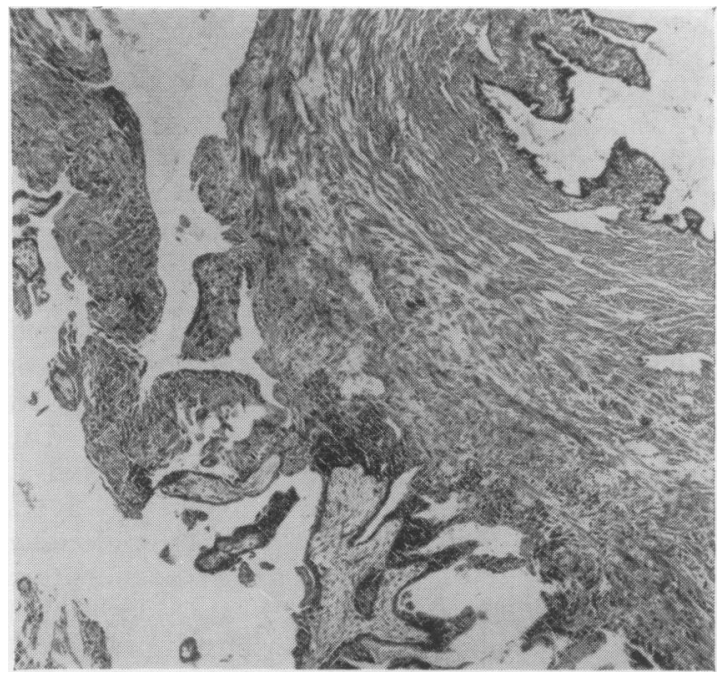

FIG. 2. Cross-section through the tubal stump showing Fallopian tube in the upper right corner and trophoblastic tissue and decidua in the lower left corner $\times 25$.

The post-operative progress was satisfactory and the patient was discharged from hospital on 18 January 1966.

\section{Discussion}

Ectopic pregnancy in the distal part of the Fallopian tube following vaginal hysterectomy (Graffagnino, 1963 ; Moayer, 1966) or abdominal hysterectomy (Ledger \& Daly, 1963) was shown to be the result of simple trapping of the fertilized ovum in the ligated tube at the time of hysterectomy.

The occurrence of pregnancy in the proximal end of a Fallopian tube following ipsilateral salpingo-oophorectomy can only be explained by the mechanism of internal migration. It is suggested that in this case the ovum must have gained entry into the uterine cavity through the normal right tube, crossed the uterine cavity and subsequently entered the left tubal stump, where it finally became implanted. Whether the ovum was fertilized before or after it reached its ultimate site of implantation need not concern us, as it does not invalidate the argument in favour of internal migration.

The possibility of the ovum gaining entry into the stump through the open abdominal end (external migration) was not considered likely because the distal end of the tubal stump was firmly fibrosed and there was no evidence of opening.

A differential diagnosis of cornual pregnancy was considered and dismissed because

1. There was no evidence of an abnormal uterine horn.

2. The round ligament was on the medial aspect of the gravid swelling.

3. The swelling was separated from the uterus by a narrower part.

4. It was sufficient to apply an artery forceps and there was no need to cut into the uterine cornu to remove the stump.

5. Generally speaking, cornual pregnancies do not rupture before the 4 th-5th month: this pregnancy was not more than 9 weeks.

6. Histological examination of the excised stump confirmed ectopic tubal pregnancy.

From the occurrence of the above case it can be concluded that whenever salpingectomy is performed on a woman of childbearing age, the Fallopian tube should be divided as closely to the respective uterine cornu as possible, so as to prevent this avoidable ectopic gestation.

\section{Acknowledgments}

I would like to thank Mr J. S. MacVine for his permission to publish this case, Dr R. A. B. Drury for the histological report and Mr A. Booker for preparing the photograph.

\section{References}

CoRTI, A. \& Ronaldi, L. (1964) Ectopic pregnancy in the site of previous adnexectomy. Osped. maggiore, 59, 413.

GRAFFaGNINO, P.G. (1963) Ectopic pregnancy following vaginal hysterectomy. Obstet. gynec. Surv. 18, 556.

LEDGER, W.L. \& DALY, M.J. (1963) Posthysterectomy tubal pregnancy. Obstet. and Gynec. 22, 514.

MOAYER, M. (1966) An extrauterine pregnancy following hysterectomy. J. Obstet. Gynaec. Brit. Cwlth, 73, 510. 